\title{
Educational Forum
}

\section{Oromucosal lesions in women smokers: an Indian perspective}

\author{
Vaishali Waghmare Shende ${ }^{1 *}$, Shruti Kaushik ${ }^{2}$, Indu Nagpal ${ }^{3}$
}

\author{
${ }^{1}$ Department of Oral Pathology and Microbiology, KMCT Dental College, Calicut, Kerala, India \\ ${ }^{2}$ Jain Sanathan Medical Center, Shalimar Bag, New Delhi, India \\ ${ }^{3}$ Dental wing World Medical College Jhajjar, Haryana, India
}

Received: 28 March 2021

Revised: 17 April 2021

Accepted: 22 April 2021

\author{
*Correspondence: \\ Dr. Vaishali Waghmare Shende, \\ E-mail: drvaishaliss@gmail.com
}

Copyright: (c) the author(s), publisher and licensee Medip Academy. This is an open-access article distributed under the terms of the Creative Commons Attribution Non-Commercial License, which permits unrestricted non-commercial use, distribution, and reproduction in any medium, provided the original work is properly cited.

\begin{abstract}
Women smoking is looked down upon by Indian society. However, a young woman smoking is not a rare sight on college campuses in metro cities. Substantial body of literature indicates that nicotine is the major component which leads to addiction. The habit which starts to look cool and fashionable in no time becomes an addiction. Indian society, which doesn't acknowledge that women are indulging in smoking, makes the whole fight about tobacco addiction a turbulent journey. As society doesn't accept that women smoke, there is no need to create awareness about its gendered impact. The study was undertaken by evaluating the oromucosal conditions and haemoglobin levels of 100 women smokers. Smokers' palate, smoking associated pigmentation on lips and calculus deposits were observed in most of the participants. The participants were not aware about the hormonal issues and detrimental side effects of smoking to their health.
\end{abstract}

Keywords: Oromucosal lesion, Women smokers, India

\section{INTRODUCTION}

Tobacco use in smokeless form is very common in India. More than 150 million men and 44 million women use tobacco in India in various forms. Globally the common and dominant form of tobacco used is in cigarette form. In India $20 \%$ of the tobacco consumed is as cigarette, $40 \%$ as bidi, the rest in various combinations of smokeless forms. ${ }^{1,2}$ There is a social acceptability and availability to male smokers in India. ${ }^{3}$ Before the tobacco prevention act, and other tobacco products act", which stopped advertising and banned smoking from public places one could see film stars and models advertising smoking brands. ${ }^{4}$ Compared to the liberty and acceptance given to males for smoking in the social and cultural fabric, none is available for women. Like in the west, there are no role models encouraging them to smoke, but the window has been opened by the internet and smart phones. The OTT platforms are not just followed for fashion, food but also have changed the lifestyle of the coming generation.

\section{Implications}

Most tobacco awareness campaigns focusing on the harmful effects of tobacco note that it will lead to oral cancer. Few campaigns focus on the second-hand exposures, especially in the Indian context where rates of respiratory infections and tuberculosis are higher compared to many other parts of the world. Additionally, there is a gender bias in tobacco awareness campaigns as they focus on men, usually ignoring the hormonal irregularities caused in women's bodies. Through this study, we want to highlight the harmful effects of tobacco on women. 


\section{Aims and objectives}

The aim of this study was to evaluate the oral mucosal changes in women smokers, to correlate the oral lesions with light smoking and heavy smoking. To correlate the haemoglobin level in light smokers and heavy smokers.

\section{METHODS}

The study was conducted in North block campus Delhi, from June 2018 to November 2018 over a period of 6 months. A total of 100 women ranging from $18-25$ years of age who gave history of smoking were given questionnaire for their smoking habits. After the duly signed consent form. Data was collected about the number of cigarettes they were smoking in a day. Thorough oral check-up was done of all the participants. The HemoCue haemoglobin photometer was used to measure haemoglobin level with the team of lion's club international blood bank van. Intra-oral photographs were taken, of the affected oral mucosa. Commonly the lesions were on lips, buccal mucosa and palate.

\section{RESULTS}

Tobacco causes a lot of variation in oral lesions. Amongst the study population 16 girls smoked 8-10 cigarettes per day. 21 girls smoked occasionally, and 58 girls smoked 14 cigarettes per day. 5 girls were almost in a phase of giving habit. Brownish black pigmentation at the cervical margins of teeth caused by tar and other by products of combustion was a common finding in all the study participants.

Palatal lesions (nicotinic stomatitis) and nicotine deposits on the lingual side of anterior teeth were very prominent in the group who smoked heavily.

Melanin pigmentation on the buccal mucosa and calculus deposition on the lingual surfaces of anterior teeth was seen in girls who were light smokers.

The haemoglobin level was significantly low in girls who smoked 8-10 cigarettes daily compared to the girls who were light smokers. Abrasion from pipe smoking on the occlusal surface was seen in 2 girls who frequently smoked hookah. Keratotic white patches were seen on the lips at site where the cigarette was retained in almost $68 \%$ of the study population.

\section{DISCUSSION}

India, which is second only to China in terms of tobacco consumption, has had anti-tobacco legislation since 1975. The actual implementation started in 2003, (COTPA) "Cigarettes and other tobacco products act", which stopped advertising and banned smoking from public places. It is important to understand various factors that influence and encourage young teenagers specially girls to start smoking or to use other tobacco products. ${ }^{5,6}$ The social atmosphere in India is not conducive for women smokers like the western counter parts. Despite this smoking is disproportionately frequent among women in India. The reasons given for taking up smoking were peer pressure. To look fashionable at the same time many wanted to look thin and they thought smoking is the easiest thing to do. To maintain the weight, to be fit and in shape. Nicotine activates a pathway in the brain that suppresses appetite is a well-known fact. The appetite suppression is making all these young women eat less, causing micronutrients loss., ${ }^{7,8}$ indirectly making them anemic. The age window in our study population was not huge. So, the frequency of cigarettes was directly proportional to the nicotine deposits on teeth, smoker's palate and white patches on the lip irrespective of the age. 9,10

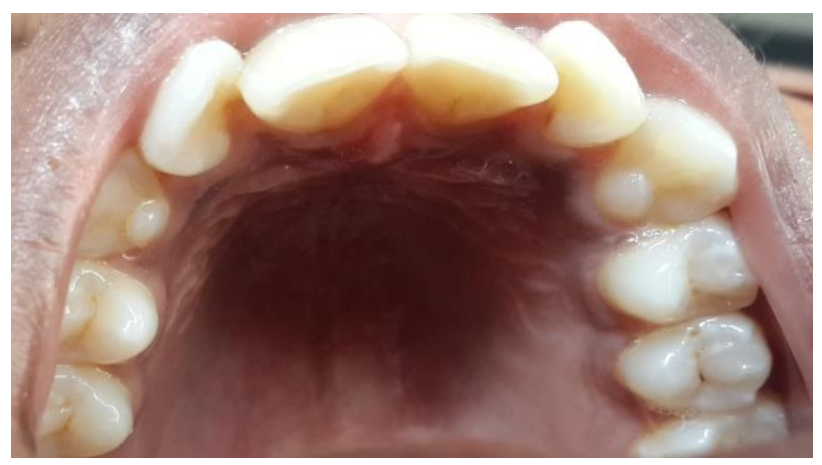

Figure 1: Palatal lesion.

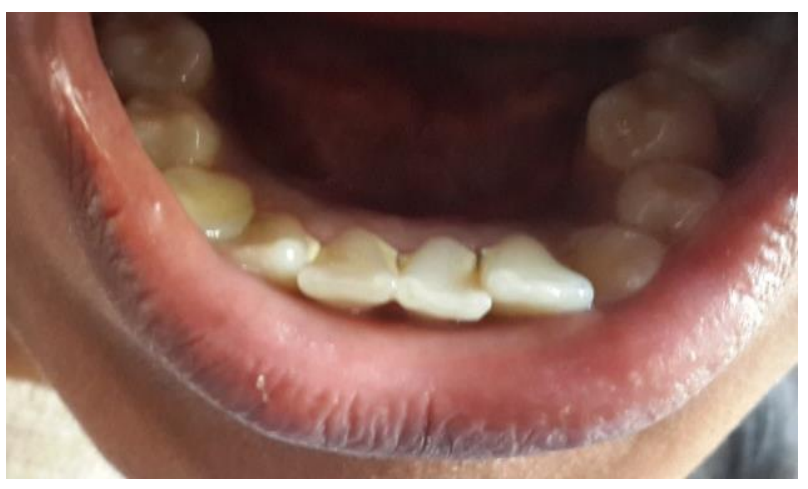

Figure 2: Plaque deposition on lower anterior.

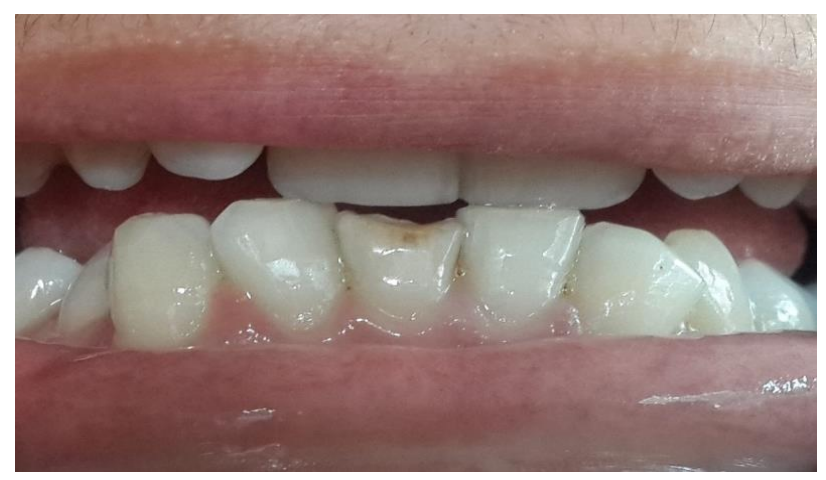

Figure 3: Chipped out central incisor due to hookah habit. 


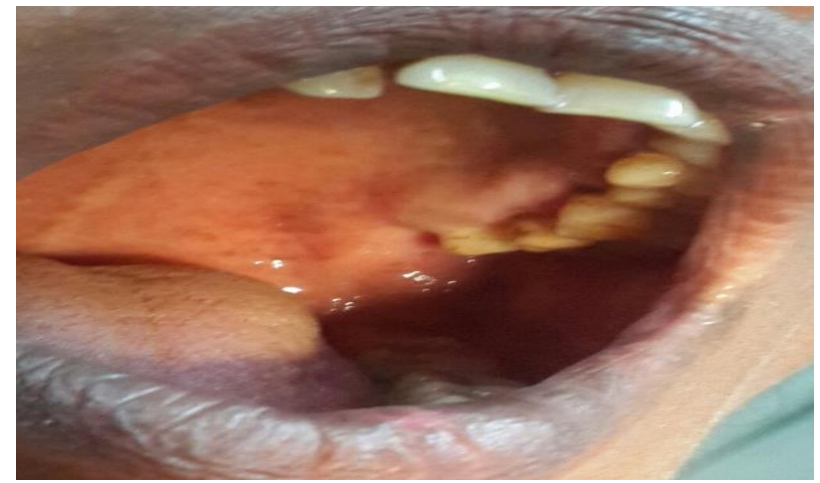

Figure 4: Typical lesion on lips.

\section{CONCLUSION}

Socioeconomic status and material deprivations are supposed to be major social determinants of tobacco habit, including both smoking and smokeless forms of tobacco use. Our study contradicts these parameters. All our study group volunteers were from educated and well to do families.

The phenomenon of social smoking appears as a risk factor for tobacco use. This study shows that social peer pressure is the major factor for taking up smoking habit. Very few had the knowledge of smoking related menstrual irregularities, PCOD and Anaemia.

Our study shows that providing psychological and behavioural guidance and timely interventions of women's awareness to smoking might be able to decline and reduce the smoking.

\section{ACKNOWLEDGEMENTS}

Author would like to thanks to Dr. Vijay Mehta in charge of lion's blood bank-East Delhi. A unit of lion's club's trust. We are thankful for the help of lion's blood bankEast Delhi. We acknowledge the help and support given by Dr. Vijay Mehta and her team.
Funding: No funding sources

Conflict of interest: None declared

Ethical approval: The study was approved by the Institutional Ethics Committee

\section{REFERENCES}

1. Kamala KA, Sankethguddad S, Nayak AG, Sanade AR, Rani SRA. Prevalence of oromucosal lesions in relation to tobacco habit among a Western Maharashtrian population. Ind $\mathbf{J}$ of Cancer. 2019;56(1):15-8.

2. Routh HB, Bhowmik KR, Parish JL, Parish LC. Historical Aspects of Tobacco Use and Smoking. Clin Dermat. 1998;16:539-44.

3. Schane RE, Ling PM, Glantz SA. Health Effects of Light and Intermittent Smoking. Circul. 2010;121:1518-22.

4. Amos A, Haglund M. From social taboo to "torch of freedom": The marketing of cigarettes. Tob Cont. 2000;9:3-8.

5. Hedin CA, Pindborg JJ, Axell T. Disappearance of smoker's melanosis after reducing smoking. J Oral Pathol Med. 1993;22:228-30.

6. Brown FH, Houston GD. Smoker's melanosis: a case report. J Periodontol. 1991;62:524-7.

7. Bowles WH, Wilkinson MR, Wagner MJ, Woody RD. Abrasive particles in tobacco products: a possible factor in dental attrition. J Am Dent Assoc. 1995; 126(3):327-31.

8. Solomon HA, Priore R, Bross I. Cigarette smoking and periodontal disease. J Am Dent Assoc. 1968;77:1081-4.

9. Haber J, Kent RL. Cigarette smoking in a periodontal practice. J Periodontal. 1992;63(2):100-6.

10. Regezi JA, Sciubba JJ, Jordan RCK. Oral Pathology: Clinical Pathologic Correlations. St. Louis, Missouri: Elsevier. 2017.

Cite this article as: Shende VW, Kaushik S, Nagpal I. Oromucosal lesions in women smokers: an Indian perspective. Int J Community Med Public Health 2021;8:2619-21. 